\title{
Flexible converters for meshed HVDC grids: From Flexible AC transmission systems (FACTS) to Flexible DC grids
}

\author{
Oriol Gomis-Bellmunt, Senior Member, IEEE, Joan Sau-Bassols, Student Member, IEEE, \\ Eduardo Prieto-Araujo, Member, IEEE, and Marc Cheah-Mane, Member, IEEE,
}

\begin{abstract}
Flexible Alternating Current Transmission Systems (FACTS) have achieved to enhance the flexibility of modern AC power systems, by providing fast, reliable and controllable solutions to steer the power flows and voltages in the network. The proliferation of High Voltage Direct Current (HVDC) transmission systems is leading to the opportunity of interconnecting several HVDC systems forming HVDC Supergrids. Such grids can eventually evolve to meshed systems which interconnect a number of different $\mathrm{AC}$ power systems and large scale offshore wind (or other renewable sources) power plants and clusters. While such heavily meshed systems can be considered futuristic and will not certainly happen in the near future, the sector is witnessing initial steps in this direction. In order to ensure the flexibility and controllability of meshed DC grids, the shunt connected AC-DC converters can be combined with additional simple and flexible DC-DC converters which can directly control current and power through the lines. The proposed DC-DC converters can provide a range of services to the HVDC grid, including power flow control capability, ancillary services for the HVDC grid or adjacent grids, stability improvement, oscillation damping, pole balancing and voltage control. The present paper presents relevant developments from industry and academia in the direction of the development of these converters, considering technical concepts, converter functionalities and possible integration with other existing systems. The paper explores a possible vision on the development of future meshed HVDC grids and discusses the role of the proposed converters in such grids.
\end{abstract}

Index Terms-Current flow converters, HVDC systems, HVDC grids, flexible power systems, FACTS.

\section{INTRODUCTION}

$\mathbf{M}$ OST countries worldwide have set a series of ambitious climate and energy targets to combat climate change while increasing energy security. While the strategy is very dependant on the policies in each specific country, the role of offshore generation (especially wind) will be decisive in order to meet current and future energy challenges. Offshore wind power plants present a number of benefits compared to traditional onshore installations [1]: the availability of higher wind speed, the possibility of transporting very large structures (allowing larger wind turbines) and the limited available inland

The authors are with the Centre d'Innovació Tecnològica en Convertidors Estàtics i Accionaments, Departament d'Enginyeria Elèctrica, Universitat Politècnica de Catalunya, Barcelona 08028, Spain. E-mail: oriol.gomis@upc.edu. E Prieto-Araujo is also a Serra Húnter Lecturer. This work was partially funded by FEDER / Ministerio de Ciencia, Innovación y Universidades - Agencia Estatal de Investigación, Project RTI2018-095429B-I00 and by the FI-AGAUR Research Fellowship Program, Generalitat de Catalunya. locations to install new wind farms in some countries (mainly in Europe).

Offshore generation facilities can be connected to the main $50 \mathrm{~Hz}$ or $60 \mathrm{~Hz}$ AC grid using transmission systems based on $\mathrm{AC}$ or $\mathrm{DC}$ technology [1]. The choice between these technologies depends on the cost of the installation which depends in turn on the transmission distance and power rating. The need to compensate for the impedance of the cables in AC transmission makes its price grow with the distance at a higher rate than DC transmission whereas DC transmission implies a high fixed cost due to the need of large power converters. Thus, there is a break-even distance from which the DC option becomes lower priced than AC [2]. For submarine cables the break-even distance is usually around $100 \mathrm{~km}$.

Until the last decade, high voltage direct current (HVDC) transmission systems were mostly based on current fed LineCommutated Converters (LCC). New converter topologies and lower priced fast-switching semiconductors made possible to build Voltage-Sourced Converter (VSC) based HVDC transmission systems. The benefits of using VSC and fast switching are the ability to independently control the active and reactive power while reducing the size of the output filters needed to have a low harmonic distortion [1], [2]. This last benefit is especially relevant for offshore applications where the footprint and weight of the converter stations is a critical issue. Novel VSC-HVDC designs based on modular multilevel converters (MMC) are arriving to efficiencies close to LCC converters. One drawback of VSC-HVDC is that the achieved voltage and current levels (although it has been increasing substantially in the last decade) is still lower than LCC. In any case, mainly due to the footprint and weight issues, all the offshore power plants which need a DC cable connection are being planned with VSC-HVDC transmission technology. The worlds first VSC-HVDC for offshore power transmission (BorWin1) was successfully commissioned off the coast of Germany in 2009. A number of VSC-HVDC converter stations for offshore wind power plants (DolWin 1, $2 \& 3$, BorWin 2, HelWin 1\&2, SylWin 1\&2) are being installed and commissioned in the North Sea since then. While VSC-HVDC technologies based on MMC have motivated a great break-through in power transmission technology, remote offshore wind power plants have a crucial challenge which needs to be addressed: the cost of the overall offshore wind power plant, also including the platforms, is very expensive.

Industry and academia have responded to this challenge 
by proposing some alternative designs which aim at reducing cost in different subsystems: diode rectifiers or LCC-HVDC converters can be used in the offshore converter station [3], [4]; Hybrid VSC/LCC transmission technology can be used with different converters onshore and offshore [5], [6]; Series or hybrid series-parallel DC collection grids for offshore wind farms can be used [7], [8]; Converter reduction or elimination in the wind turbines, by using the VSC-HVDC converter to modulate the offshore frequency and the average wind turbine speed [9], [10]. While the proposed solutions bring some promising ideas for cost reduction of offshore wind power plants, the integration of these systems with the HVDC transmission can bring some new technical challenges for the transmission links. A clear example is the possible deployment of converter stations based on diode rectifiers. Such a technology can bring a cost reduction, but the lack of controllability of the diodes will pose some operation, protection and stability challenges which need to be addressed.

It is important to remark that converter stations based on technologies not able of forming a grid (such as diode rectifier units and LCC converter stations) require external devices to form the offshore AC grid and control the frequency. This can be provided by an appropriate coordinated control of a plurality of wind turbines running in grid forming mode, or by additional equipment such as STATCOM systems or batteries interfaced with Voltage Source Converters (VSC). These options have been studied in references [11]-[13] and are being explored in the frame of the EU project Promotion [14] and have been proposed by relevant manufacturers [15].

Currently, existing VSC-HVDC transmission systems in Europe use point-to-point connections. This means that each individual converter is directly connected to another single converter by means of a DC cable. More terminals can be added (keeping a radial structure) evolving into the so-called multiterminal HVDC (M-HVDC) scheme. Two multiterminal (Nan'ao, 3 terminals, and Zhoushan, 5 terminals) HVDC projects are already in operation in China [16], while some projects are under study in the rest of the world. Furthermore, there exist the opportunity to create meshed HVDC grids offshore, both interconnecting different countries and transmitting all the offshore power generated.

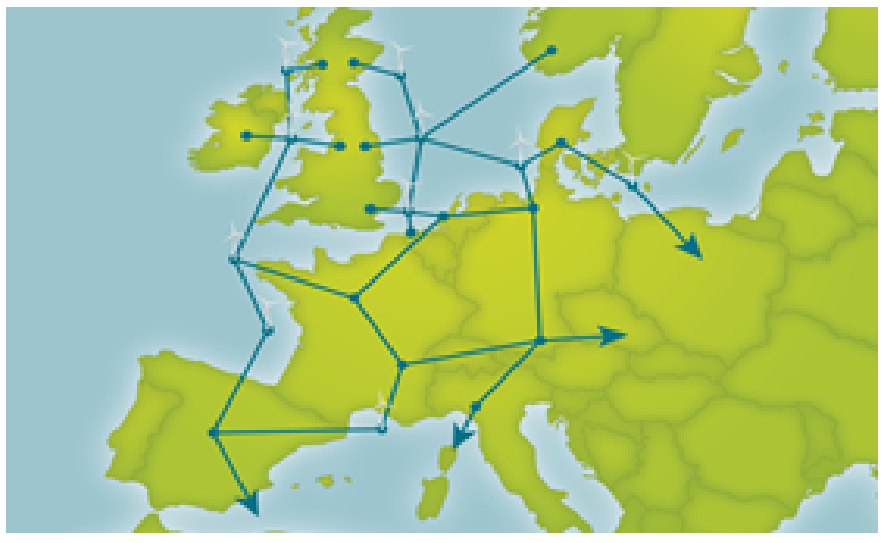

Figure 1. The European Supergrid. Source: Friends of the Supergrid

The offshore grid alternative can eventually evolve in the so called Supergrid [17] (Figure 1 shows the vision of the European Supergrid). Such a concept shows a number of advantages (comparing to other transmission options such as point to point HVDC or HVAC) and is definitely optimum but requires standardization and coordination. On the other hand, some initiatives (the most relevant in Germany [18]) are targeting at reinforcing AC power systems by introducing large VSC-HVDC links interconnecting the offshore generation plants with the load centres.

The development of HVDC grids presents a number of technical challenges (There are also a number of non-technical challenges which are extremely important, including economical, ownership and legal aspects): optimum topologies definition considering cost optimization and system reliability; Development of reliable, efficient and cost effective power converters (DC-DC and DC-AC) able to create independent grids and provide support to the main AC systems; Development of technologies to ease the controllability of power flows; HVDC circuit breaker technology with reasonable cost and efficiency; Fast and reliable systems for fault detection and isolation; Power flows control and optimization; Voltage control in normal and fault conditions. The previously mentioned challenges are certainly important and need to be (and are being) addressed in the short-medium term in order to allow the development of HVDC grids.

The present paper is organized on the basis that future HVDC grids will be very complex systems, incorporating a number of different power converters of different nature. Such hybrid grids will be composed of VSC converters (2-level, MMC half bridge and MMC full bridge), thyristors-based LCC converters, diode rectifier based converters and DC-DC converters of different nature [19], [20]. The hybridization will allow the interconnection of different sub-systems but will also imply severe limitations on the operational capacity of the involved converters. Specific power converters and apparatus will be required to control the power flows, protect the power system and ensure stability.

The present paper combines a revision of the state of the art in the topic, with a vision on future meshed HVDC grids including the proposed converters. It presents some different developments from industry and academia on flexible DCDC converters to be able to develop flexible HVDC grids. The paper addresses different technical concepts, converter functionalities and possible integration with other existing systems. The paper envisions future HVDC grids where the proposed converters can be integrated with other equipment like HVDC circuit breakers, to achieve the required flexibility at a reasonable cost. The rest of the paper is structured as follows. Section II synthesizes the state of the art and summarizes the main technologies proposed. Section III presents the vision of future HVDC meshed grids with the proposed flexible DC-DC converters. Section IV elaborates on the main features that characterize the proposed converters and presents some results which prove these features. Section V discusses trends, challenges and research needs. The conclusions are summarized in Section VI. 


\section{STATE OF THE ART}

Current Flow Controllers (CFCs) or Power Flow Controllers (PFCs) are power converters of full or reduced size that can be used to support the overall control of an HVDC grid. There are three main categories of devices that can be used as CFC depending on the way they are connected to the HVDC grid: parallel-connected, series-connected and parallel-seriesconnected devices. These concepts are illustrated in Fig. 2.

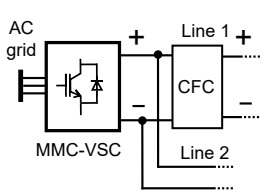

(a)

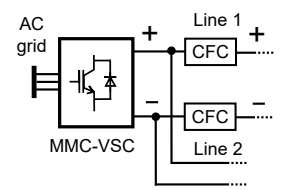

(b)

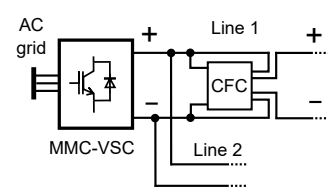

(c)
Figure 2. CFC concepts. (a) Parallel-connected. (b) Series-connected. (c) Series-parallel-connected.

\section{A. Parallel-connected CFCs}

Parallel-connected devices are connected between the positive pole and the negative pole of the transmission system [21], [22]. They are essentially DC-DC transformers with a voltage transformer ratio between the input and the output that are used to interconnect HVDC systems with different voltage level and can provide other functionalities as power flow control [23]. The main drawback of parallel-connected devices is that they have to withstand the nominal voltage of the transmission system and need to be rated for the full power flowing through the device, which can mean hundreds of megawatts. Therefore, this leads to high costs not always justifiable for only power flow applications [24].

\section{B. Series-connected CFCs}

Series-connected CFCs can be smaller devices and are floating at the positive or negative pole of the HVDC system inserting a variable voltage in series with the line [21]. Therefore, they must not be rated for the nominal voltage of the transmission system but for the nominal current of the line. With few $\mathrm{kV}$ it is possible to regulate tens or hundreds of amperes since the cable resistances are very low [21]. This fact may diminish their cost, compared to parallel-connected CFCs and can make them more convenient to regulate current flows. Another consideration regarding series devices is that they have to be placed in the positive pole and also in the negative pole, otherwise the symmetry of the current flow is lost in the HVDC grid [23]. They can be classified as: series variable resistors, AC-DC converters and DC-DC converters.

CFCs based on series variable resistors achieve the variable voltage by means of a variable resistance in series with the line. A series variable resistor can be inserted in the DC grid to directly modify the resistance of the line. It allows to apply only positive voltage which reduces the current through that cable. Its main disadvantage is that the losses of the system get increased and may require additional cooling equipment [24], though, its simplicity is a key factor to take into account. A scheme of the series variable resistor is shown in Fig. 3.
Similar techniques have been applied in AC systems for fault ride-through of wind turbines [25].

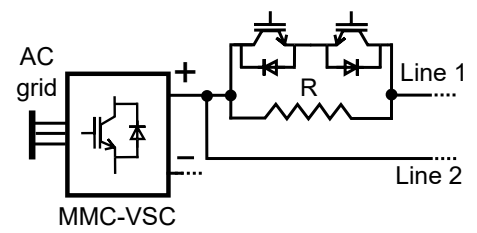

Figure 3. Series variable resistor.

AC-DC converters exchange power between the AC system and the HVDC grid. Therefore, they apply positive or negative voltage in series with the line where they are connected and this allows to regulate the current flow. The voltage applied depends on the external AC source and the converter topology. An isolation transformer is required to be floating at the positive pole or the negative pole, so that the device does not need to withstand the nominal voltage of the DC system, but only a small percentage of it [21].

Several topologies of AC-DC converters for power flow control have been proposed in the literature. An AC-DC controller made of two six-pulses thyristor converters connected in dual-configuration is presented in [26]. It allows fourquadrant operation but it cannot control active and reactive power independently. The advantages lie in the simplicity and reliability of thyristor converters and their low losses. Fig. 4(a) depicts the scheme of the thyristor-based CFC.

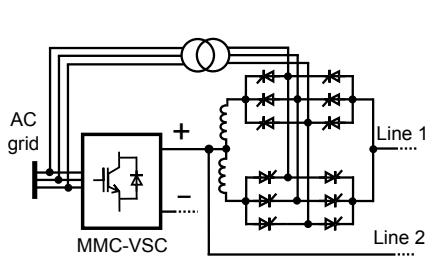

(a)

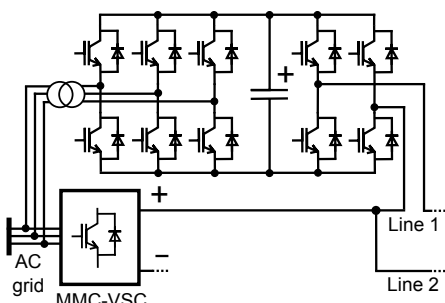

(b)
Figure 4. CFCs based on AC-DC converters. (a) Thyristor-based CFC. (b) IGBT-based CFC.

Another proposal regarding AC-DC converters for power flow is the concept introduced in [27], [28]. The converter is shown in Fig. 4(b) and is made of a two-level, three phase VSC and a four-quadrant chopper. The two-level VSC maintains the capacitor voltage constant, while the chopper regulates DC current by generating a variable mean DC voltage on the DC line. The chopper allows to operate with any direction of line current (four-quadrant operation). This topology is more flexible since allows reactive power regulation in the AC side. Nevertheless, converter losses can be higher in comparison with the thyristor-based converter [26]. In [29], an analogous AC-DC converter but based on modular multilevel current source technology [30] is presented.

DC-DC converters based CFCs exchange power between different lines of the HVDC system, thus they are also called interline CFCs [31]. They do not require an $\mathrm{AC}$ grid to create the variable voltage source, therefore, the $\mathrm{AC}$ isolation transformer is not needed. In comparison with the AC-DC converters, the variable voltage they can apply is limited by the HVDC line currents and the converter topology. They are also 
floating at the HVDC poles and the power extracted from one line is injected into the other line, applying positive voltage in one line and negative voltage in the other line if currents flows have the same direction.

One of the first DC-DC converters for current flow control was proposed in [32], [33]. It consists on two H-bridges, each one connected to one HVDC line. Fig. 5(a) shows the presented topology, which was chosen to take advantage of the standard VSC full bridge cell [32]. An alternative topology with the same functionality is depicted in Fig. 5(b), which consists on merging the two capacitors and removing the redundant switches. It allows to apply positive or negative voltage in any line, and it is prepared to operate with any current flow through the lines. The capacitor is used to exchange power between the two HVDC lines. This converter is analysed in [34], [35]. In [36], an experimental validation of this CFC topology is also provided along with the coordination and control of two of these converters in the same HVDC grid.

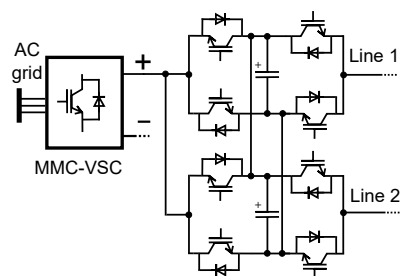

(a)

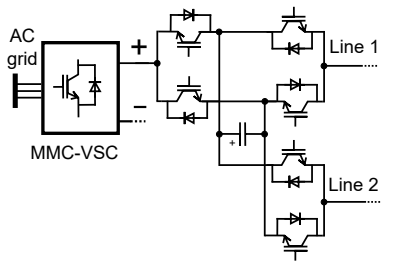

(b)
Figure 5. Dual H-bridge. (a) General topology. (b) Simplified topology.

Another proposal of an interline DC-DC converter for power flow regulation is presented in [31]. Although this converter is made of two H-bridges as well, their switches require reversevoltage blocking capability since capacitor voltages can be positive or negative. Introducing a diode in series with each IGBT is one option to achieve such capability. This device also allows to operate with any current flow. The element which exchanges power with the two H-bridges is an inductance (made of an inductance plus an isolation transformer), instead of the capacitor used in [32]. The general topology scheme is depicted in Fig. 6(a).

When considering a 3-terminal meshed DC grid, the previous topology can be simplified into Fig. 6(b). This converter topology is rather simple but it allows to operate only when line currents are entering the CFC, so that the MMC-VSC in Fig. 6(b) is acting as an inverter.

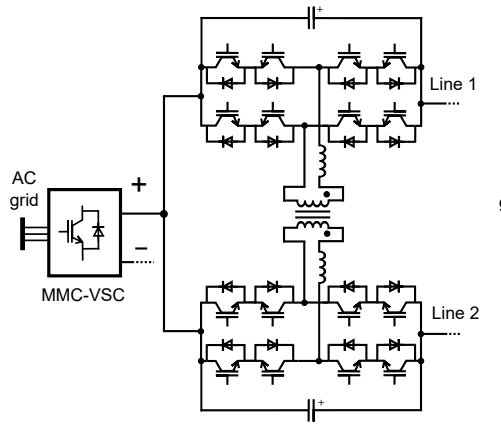

(a)

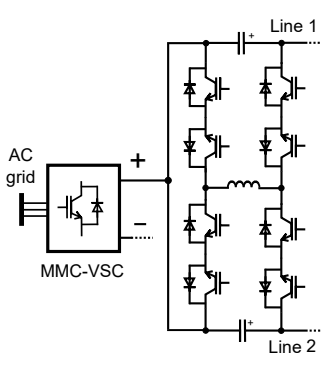

(b)
Figure 6. Interline DC-DC topology. (a) General topology. (b) Simplified topology.
The same authors introduced and enhanced interline CFC topology that can operate with any current flow direction and at the same time has a rather simple structure [37]. The CFC structure is depicted in Fig. 7. Another modification of this CFC topology can be found in [38], where the CFC is able not only to provide bidirectional power flow but also to be connected to HVDC lines with different voltage level.

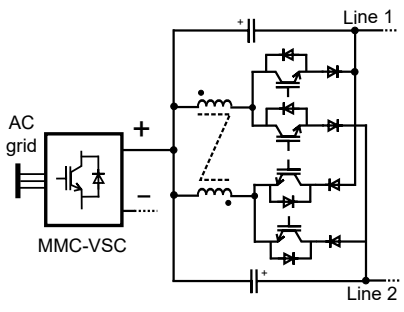

Figure 7. Enhanced interline DC-DC topology.

In [39], a simplified interline DC-DC CFC structure for unidirectional current flow control is introduced and analysed, which was presented in [40], [41]. The two possible converter structures of the aforementioned topology are shown in Fig. 8.

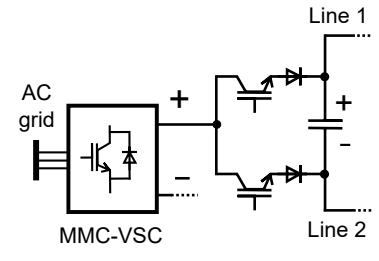

(a)

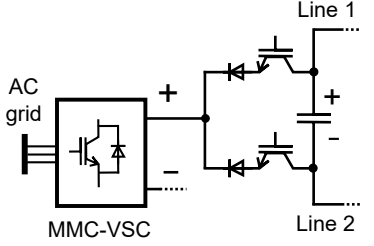

(b)
Figure 8. Series interline DC-DC unidirectional CFC. (a) Structure when the currents of line 1 and 2 are going out the device. (b) Structure when the currents of line 1 and 2 are going in the device.

In [42] two variable resistors are added in each HVDC line in series to the CFC structure in Fig. 6(b) in order to have additional degrees of freedom. This represents a combination of the series variable resistor CFC and an interline DC-DC CFC.

References [43], [44] are based on the design presented in Fig. 6(a), but they incorporate an additional H-bridge between the AC transformer and each HVDC line, obtaining an additional DC stage at each side.

Due to the fact that CFCs are going to be installed in HVDC grids, where the converters terminals are expected to be MMCs, it is reasonable to think of CFCs made of MMCs submodules. Several authors suggested CFC cell-based converter structures based on submodules of MMCs that provide easy scalability and modularity to be adapted to different voltage levels at the expense of having more complex structures.

For instance, in [45], two 3-phase MMCs based on fullbridge submodules are connected through the $\mathrm{AC}$ side via an $\mathrm{AC}$ transformer in a Front-to-Front $(\mathrm{F} 2 \mathrm{~F})$ configuration and the DC sides of each MMC are connected to different HVDC lines. The MMCs exchange power through the $\mathrm{AC}$ side to apply series voltages on the lines to regulate the current flows and a scheme of the converter structure can be found in Fig. 9(a).

Another proposal of a modular and scalable CFC based on full-bridge submodules is presented in [46] and depicted 
in Fig. 9(b). This converter does not require an isolation transformer and is made of 5 cell-based arms. Arms 1 and 2 inject the required DC voltage to perform the current control, while at the same time modulate AC circulating current between them and Arm 3 to maintain the balancing of the submodules. Arm 3 provides a short-circuit path for the AC current and Arms 4 and 5 apply the inverse AC voltage of Arms 1 and 2, respectively, in order to avoid the circulation of AC current through the HVDC lines. This CFC device offers a suitable option for high CFC voltage ratings but with some disadvantages for lower voltage ratings due to the semiconductor effort [47].

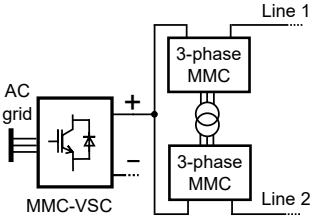

(a)

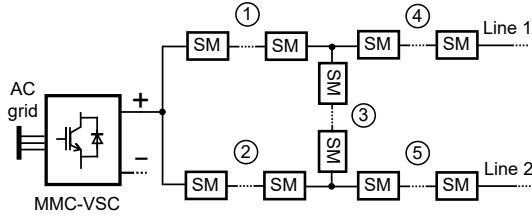

(b)
Figure 9. CFCs based on MMC structures. (a) CFC with two 3-phase MMCs in F2F configuration with an isolation transformer. (b) CFC based on 5 MMC arms without AC transformer.

As a result, the authors of the previous modular and scalable CFC device, suggested another CFC structure more suitable for medium CFC voltage ratings [47]. The circuit in [47], is based in CFC cells, each one made of full-bridge units in each HVDC line connected between them through a capacitor and bidirectional switches.

The majority of the proposed DC-DC or interline CFCs in the literature consider that the device is connected between three different ports: one HVDC node and two HVDC lines, which means that the devices can be called 3-port CFCs. However, in a highly meshed HVDC grid, the number of possible HVDC lines connected to the same node can be higher than three. As a result, researchers are also considering multi-port CFC structures that can be connected to a generic number $n$ of lines. Some multi-port CFC devices can be found in [45], [48], [49].

For example, in [48] an extended version of the Dual Hbridge presented in [32] is proposed. For each HVDC line, an $\mathrm{H}$-bridge is added and a single capacitor is connected to each H-bridge (see Fig. 10(a)).

Also, an extension of the MMC-based DC-DC CFC topology presented in [45] for a number $n$ of lines is introduced in [50].

A multi-port CFC concept based on MMC arms and called Multi-port polygon-shape is introduced in [49] and also illustrated in Fig. 10(b).

\section{Series-parallel-connected CFCs}

The series-parallel-connected CFCs are a combination of both series and parallel-connected devices. One side of the CFC is installed in series with the HVDC line and the other side is connected in parallel between the two poles of the HVDC system. The advantage of this type of CFCs is that they can control the current of the line without depending on the current that circulates through adjacent lines or external AC

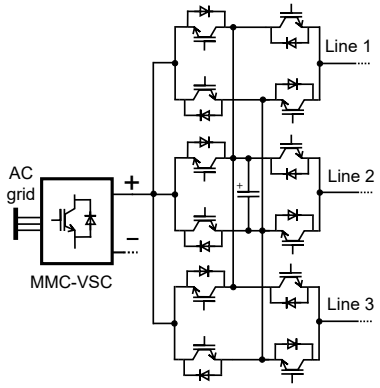

(a)

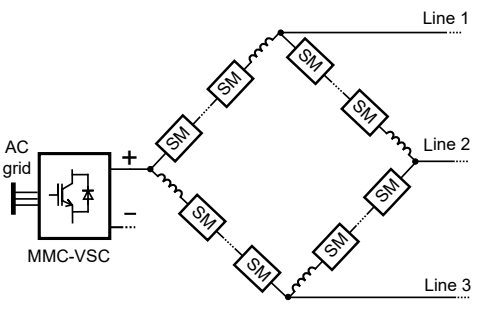

(b)
Figure 10. Multi-port CFCs. (a) Multi-port topology of the Dual H-bridge. (b) Multi-port polygon-shape CFC based on MMC arms.

connections. The CFC exchanges power between the series connection with the line and the parallel connection of the HVDC system to be able to apply a variable series voltage source in the line [51]. One drawback is that a converter to withstand the full pole-to-pole HVDC voltage is required as in parallel-connected CFCs. However, the rating of this converter can be lower, since not all the power of the HVDC system circulates through it.

The concept proposed in [51] uses a Dual Active Bridge (DAB) as a parallel-connected converter and then a extended version of the topology introduced in [37] is connected in series with two HVDC lines.

In [52], a series-parallel-connected CFC is also suggested and the work focuses the analysis on the influence of this kind of CFCs in power system studies. The average model of the CFC device is obtained and used to perform small-signal and stability analysis.

Another series-parallel-connected CFC structure can be found in [53], where a DAB is also used as a parallelconnected DC-DC converter.

A series-parallel CFC similar to the thyristor concept in [26], where the AC voltage is obtained from a AC-DC converter connected in parallel with the transmission line is proposed in [54].

Finally, a concept which can be included in the seriesparallel group, though it does not share all of its drawbacks, is the one presented in [55], [56]. The CFC is depicted in Fig. 11, where a submodule of the MMC at the node is used to generate an $\mathrm{AC}$ source via an AC-DC converter connected to the capacitor submodule. The AC source is connected through an $\mathrm{AC}$ transformer to another AC-DC converter, which has a series connection with the HVDC line and can apply a variable voltage. The previous CFC structure brings the advantages of a series-parallel CFC concept but it does not require to withstand the pole-to-pole voltage of the HVDC system. Nonetheless, this type of CFC must guarantee the proper balancing and operation of the MMC when current flow control capability is used.

\section{VISION OF COMPLEX HVDC GRIDS INCLUDING FLEXIBLE DC-DC CONVERTERS}

Both High Voltage AC and DC systems are experiencing a deep transformation. Table I includes some perspectives on 


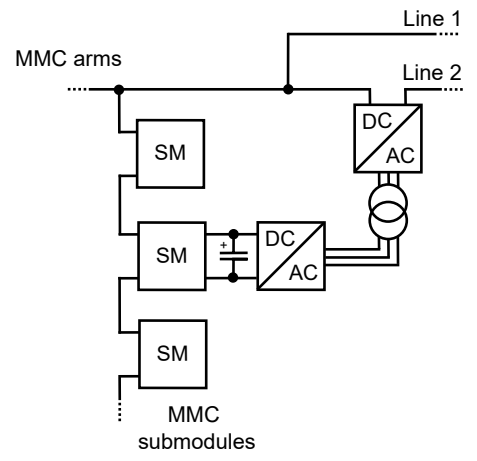

Figure 11. Series-parallel CFC connected to the MMC submodules.

key transformations than can be expected in different time horizons.

Table I

FUtURE TRANSFORMATIONS FOR High Voltage AC AND DC SYSTEMS.

\begin{tabular}{|c|c|c|}
\hline $\begin{array}{l}\text { Time } \\
\text { horizon }\end{array}$ & High voltage $\mathrm{AC}$ systems & High voltage DC systems \\
\hline Nowadays & $\begin{array}{l}\text { Dominate the power sys- } \\
\text { tem. AC is the base of } \\
\text { the power system, integrat- } \\
\text { ing an increasing amount of } \\
\text { power converters. The key } \\
\text { advantage of cheap, effi- } \\
\text { cient and reliable transform- } \\
\text { ers and protections make } \\
\text { AC the preferred choice. }\end{array}$ & $\begin{array}{l}\text { Used mainly in point-to- } \\
\text { point interconnections when } \\
\text { AC lines are not feasible } \\
\text { (very long overhead lines, } \\
\text { long cables or connection of } \\
\text { asynchronous systems). }\end{array}$ \\
\hline $\begin{array}{l}5 \text { years } \\
\text { horizon }\end{array}$ & $\begin{array}{l}\text { Total integration of } \mathrm{AC} \text { and } \\
\mathrm{DC} \text { transmission systems } \\
\text { interconnected in multiple } \\
\text { locations. Development of } \\
\text { offshore AC hubs, intercon- } \\
\text { nected with HVDC systems. }\end{array}$ & $\begin{array}{l}\text { Expected proliferation of } \\
\text { multiterminal VSC-HVDC } \\
\text { schemes interconnecting } \\
\text { different HVDC systems. }\end{array}$ \\
\hline $\begin{array}{l}15 \text { years } \\
\text { horizon }\end{array}$ & $\begin{array}{l}\text { Possible irruption of solid- } \\
\text { state transformers, moving } \\
\text { toward a pure power elec- } \\
\text { tronics AC system. }\end{array}$ & $\begin{array}{l}\text { Expected proliferation of } \\
\text { meshed HVDC systems, in- } \\
\text { cluding DC-DC converters } \\
\text { of different types. Possible } \\
\text { development of continental } \\
\text { Supergrids. }\end{array}$ \\
\hline $\begin{array}{l}\text { Long } \\
\text { term } \\
\text { horizon }\end{array}$ & 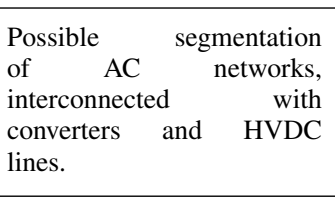 & $\begin{array}{l}\text { Possible evolution of } \\
\text { the network to a global } \\
\text { inter-continental HVDC } \\
\text { grid, making possible } \\
\text { interconnection of different } \\
\text { continents. }\end{array}$ \\
\hline
\end{tabular}

The different control approaches investigated in the last years [1], [2] have addressed the need to control the voltages and powers throughout meshed HVDC grids. However, most studies assume the usual shunt connection of the converters and therefore, the studies are not considering the possibility of using series-connected converters to further improve the system performance, especially in the case of risk of overload of some of the system lines. In practice, such overloads can cause bottlenecks in the system which can limit the power exchange capability between systems, with the consequent economic impact, when the interconnected systems have important differences in the cost of electrical energy.

\section{A. Flexible converters for meshed HVDC grids}

Series-connected CFCs can evolve to become a new breed of power converters to ensure a high flexibility in HVDC grids.
Such converters can eventually become the DC version of Flexible AC transmission systems (FACTS). These kind of converters can be needed especially when a DC grid becomes meshed, and the parallel connected converters (MMC) are not able to control the power flows in the system. It would be a case similar to series-connected FACTS in AC systems, which are used (for example) to prevent overloads in certain lines in meshed systems. Long DC cables can introduce dynamics and oscillation modes that should be considered in the stability analysis and control design of the converters, including the CFCs. In particular, the CFCs can include active damping controls to mitigate potential unstable oscillation modes.

The converter principle of operation (for most of the interline concepts) relies on inserting the capacitor alternatively in one or the other line, allowing the converter to act as two variable DC sources connected between lines. This equivalent variable DC sources allow changing the system voltages and therefore modifying the overall system power flow and allowing an enhanced system controllability. The converter has a reduced amount of energy storage (only in the DC capacitor) which can be adjusted choosing the right capacitor. In order to provide the system services (power flow control capability, stability improvement, oscillation damping, pole balancing and voltage control), the converter applies the right voltage in the voltage sources and therefore changes the overall system currents and voltages. The concept can be understood as having series FACTS (Flexible AC Transmission Systems) in DC networks, with the key difference than in DC systems reactive power is meaningless. Some of the AC-DC converters of the system (MMC based VSC-HVDC) will also have capability of providing ancillary services to the hybrid HVDC grid. These converters will be coordinated with the flexible DC-DC converters to provide the required services. The series disposition of the converters allows to provide some of the services more efficiently as they can impact more importantly the overall system power flows.

The possible integration of DC-DC converters with DC circuit breakers is especially significant, to develop a device with advanced functionalities while minimizing the cost.

\section{B. Future complex HVDC grids}

The following five concepts (Fig. 12) show some possible evolutions of HVDC transmission systems for offshore wind power plants. The baseline case is Concept 0 , which is a point-to-point VSC-HVDC transmission link. Some of the concepts discussed are natural evolutions which have been already investigated while others are more disruptive concepts:

- Concept 1: Multiterminal HVDC system. This is the natural evolution of point-to-point systems (Concept 0).

- Concept 2: Converter stations with reduced cost. Different technologies have been suggested for cost reduction of offshore converter stations. These include diode-rectifer based converters, LCC converters, DC collection grids for the offshore wind power plant, and others. Some of the concepts can potentially achieve cost reduction, also rising some technical challenges on the overall system controllability, operation and protection. 


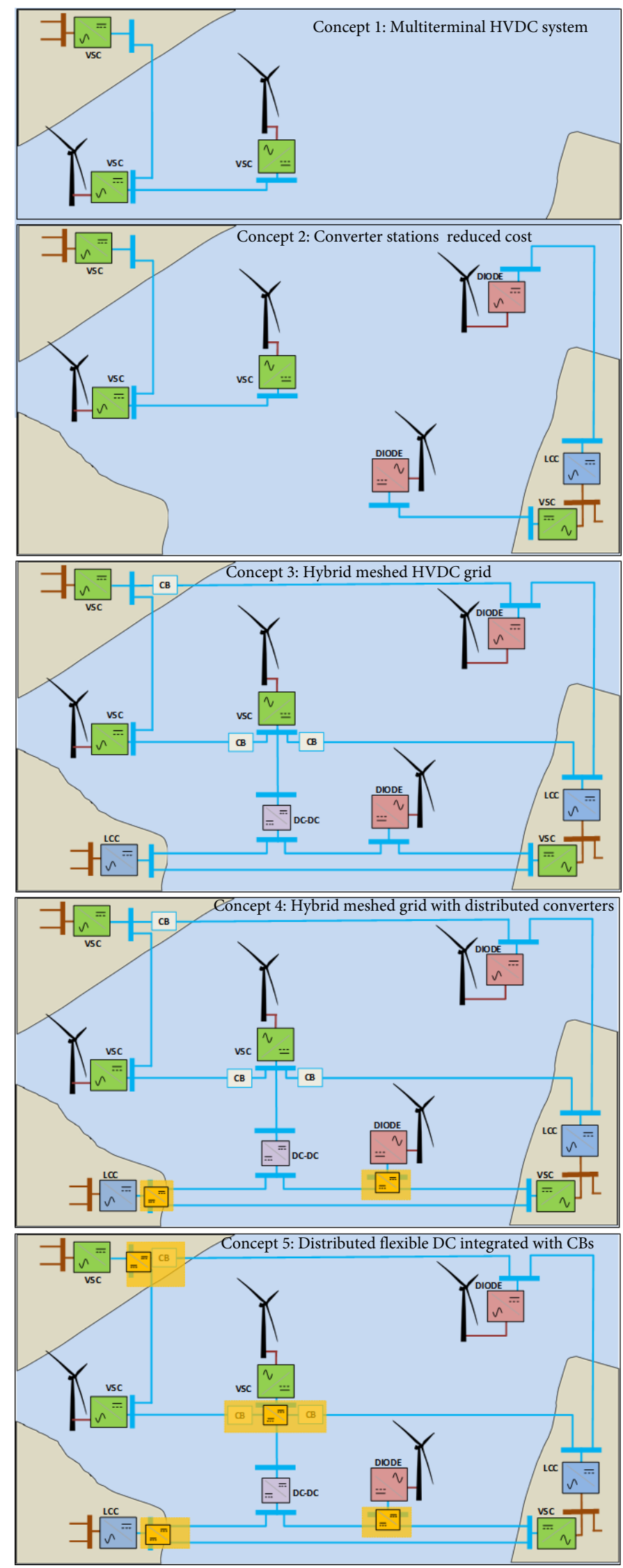

Figure 12. Possible evolutions of HVDC transmission systems for offshore wind power plants
- Concept 3: Hybrid meshed HVDC grid. The cost reduction of the converter stations and the evolution towards a meshed HVDC network are combined, resulting in a complex hybrid system including converters of different nature. Circuit breakers are also required to define different protection zones and avoid in whole system loss whenever a fault in the DC grid occurs.

- Concept 4: Hybrid meshed grid with distributed converters. Flexible DC-DC converters (of low cost, because of their lower power rating) are proposed. Flexible DC-DC converters will be used for multiple services including power flow control, ancillary services for the HVDC grid or adjacent grids, stability improvement, oscillation damping, pole balancing and voltage control.

- Concept 5: Hybrid meshed grid with distributed flexible DC-DC converters and flexible DC-DC converters integrated with HVDC circuit breakers. The concept of integration of flexible DC-DC converters with HVDC circuit breakers can enable the utilization of flexible DCDC converters at almost no cost, since all the required components are already available in the HVDC circuit breakers.

The overall cost of Concept 1 is high because it is based on using VSC-HVDC in all the converter stations. The overall cost is reduced in Concept 2, by using simpler and less controllable converters. Further reductions are obtained in Concept 3 by using a meshed grid, and using it for power exchange between countries and to increase the reliability of the transmission of offshore generated power. Concept 3 is likely to be unstable (for the lack of controllability), and therefore Concept 4 is proposed at the cost of increasing the CAPEX by adding the proposed flexible DC-DC converters. This CAPEX increase is compensated by the OPEX reduction for the improved system reliability and availability. Concept 5 integrates the flexible DC-DC converters converters with HVDC circuit breakers, and therefore it achieves OPEX improvement without increasing the CAPEX.

It is important to remark that while Figure 12 covers a complex HVDC grid with different technologies of power converters, the proposed converter will be also needed in different possible scenarios with less variability of power electronics converters.

Fig. 13 shows an example of an eventual future European HVDC grid including multiple different technologies in the converter stations (Concept 3). The illustrated concept does not pretend to show the best possible future solution, but to exemplify a possible hybridized network that can eventually exist as a result of a complex history of decisions taken by several transmission system operators, regulatory bodies, offshore renewable projects developers and HVDC technology providers. The upper subfigure includes a network divided into 5 different protection zones (to minimize the number of HVDC circuit breakers) including LCC-HVDC, VSC-HVDC and DC-DC converters The different circled numbers in Fig. 13 , indicate the different protection zones). In such a highly hybridized system, the overall system controllability and stability is an important challenge. The utilization of the flexible DC-DC converters is suggested (subfigure below, Concepts 
4 and 5) to deal with the control of the overall power flows and maintain the system stability. The proposed converters are small power converters connected in series used to control the power flows, ensure the operation at the reference voltage, damp oscillations, while ensuring proper operation in normal and fault conditions (for faults in the DC and AC systems). The converter is integrated in some cases with one or several circuit breakers. It can be noticed that power converters with multiple output channels will be required.

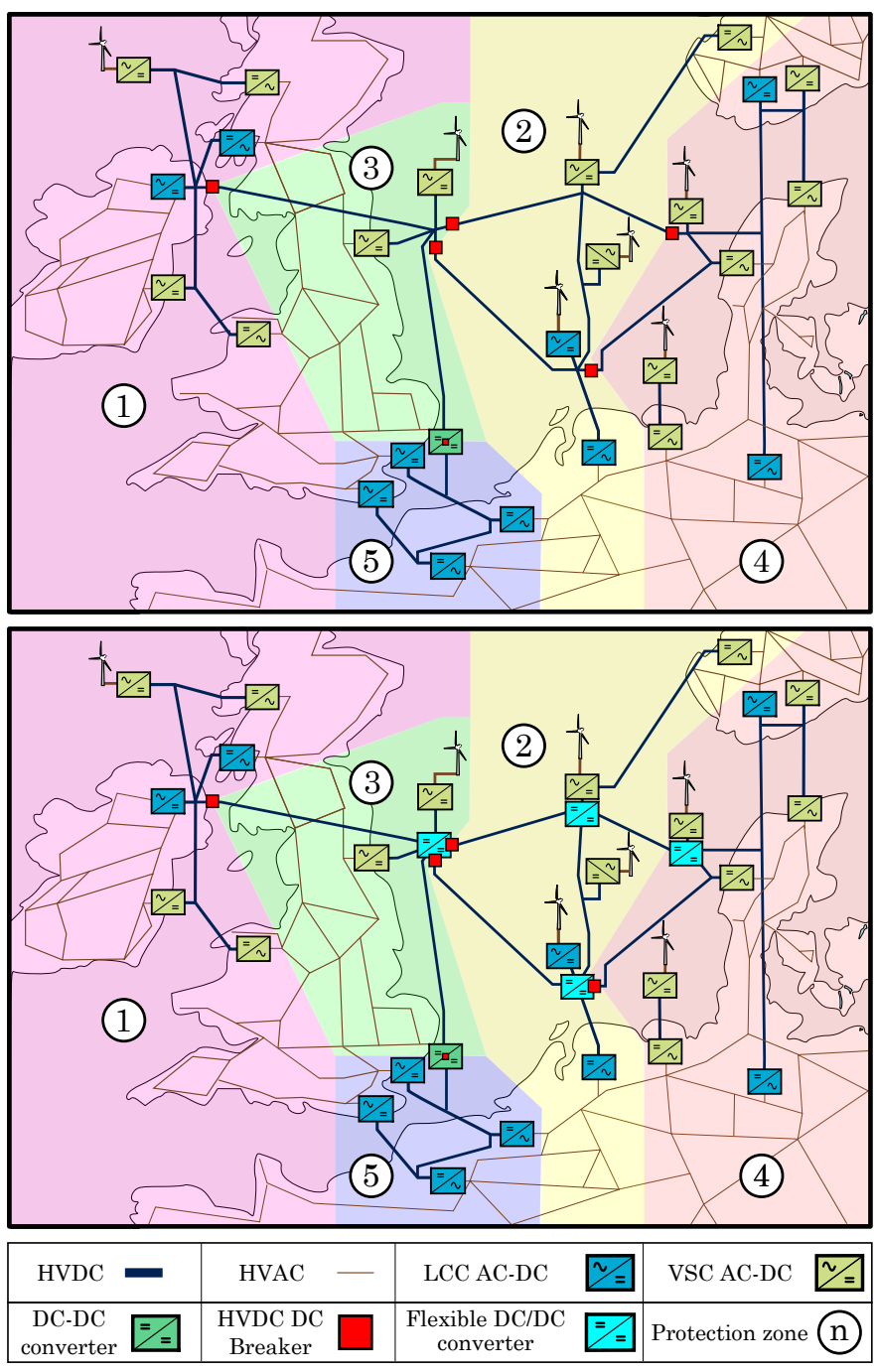

Figure 13. Example of a possible future European HVDC grid

\section{FLEXIBLE DC-DC CONVERTERS FOR HVDC GRIDS}

The following features characterize the proposed concept:

1) Small: Converters will be rated at full line current, but rated to limited voltage, approximately $1-5 \%$ of the HVDC rated voltage. Therefore, the device rated power will be of $1-5 \%$.

2) Multifunctional: Converters will provide a range of functionalities, including power flow control capability, ancillary services for the HVDC grid or adjacent grids, stability improvement, oscillation damping, pole balancing and voltage control. The converters can help to mitigate possible perturbations or oscillations caused by specific power converter solutions in the AC-DC converter stations.

3) Distributed: A number of devices will be installed in the network in order to guarantee an optimal system operation and maximize efficiency and reliability.

4) Integrated: The converter will be integrated with HVDC circuit breakers. This will allow a multifunctional circuit breaker, combining the functionalities of the two devices.

5) Secure: As it is not a protection device, the converter needs to be protected or integrated (previous point) by other elements of the system. The converter will have to be coordinated with appropriate circuit breakers to ensure the safe operation. The converter will include a bypass which will be activated when the converter is not operating and it can also be used in fault condition.

6) Efficient: Due to the reduced power rating of the converters, the losses are expected to be also low. In [32], the losses of the Dual H-bridge CFC are stated to be around $24 \mathrm{~kW}$ and in [57], for the converter in Fig. 21(a), are calculated to be between $8-23 \mathrm{~kW}$, depending on the operational point. In both cases the converters are steering hundreds of MW.

7) Reliable: The converter complexity is reduced, due to the rating of $1-5 \%$ of the HVDC voltage. For instance, the CFC device presented in [32] is thought to be made of two MMC full bridge cells and other works consider a reduced number of switches in series to withstand the required voltage [39]. While expected failure rates are very low, as it is a series-connected converter, it is needed to employ a bypass switch which will be activated in case of any failure in the converter. The distributed concept, discussed in Subsection IV-B, contributes significantly to improve the reliability of the concept as a number of devices are introduced in the system and some of them can be used to provide a similar service in case of failure, bringing extra redundancy.

In the rest of the Section, some research results and ideas are exposed in order to enhance the presented features.

\section{A. Small series connected interline converters}

The converters can be considered small because they have power rating which is a small fraction of the power they are handling ( 1 to $5 \%$ as example). This Section shows the simulation and experimental results of the interline DC-DC CFC [39], [40] illustrated in Fig. 8(a). The operation of the device consists on inserting a capacitor in series with the lines where it is connected by closing its switches in a complementary manner. The current of the lines can be regulated based on the previous operation and the CFC capacitor achieves a certain voltage that ensures the desired current relation. Also, the duty cycle sent to the switches establishes the current relation in steady-state [39].

The HVDC grid used in the simulations is shown in Fig. 14 and the results are depicted in Fig. 15, where a current 
reference for $I_{41}^{*}$ is given to the CFC and it is maintained also when the power of the nodes change, demonstrating the current control capability of the device. The coordination between the converter and the protection system is not included in the present paper, but it has been addressed in [58] A experimental

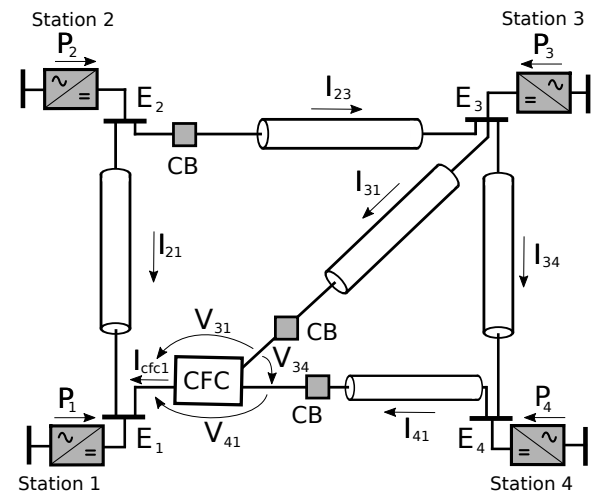

Figure 14. 4-terminal meshed HVDC grid with the CFC installed in Node 1.
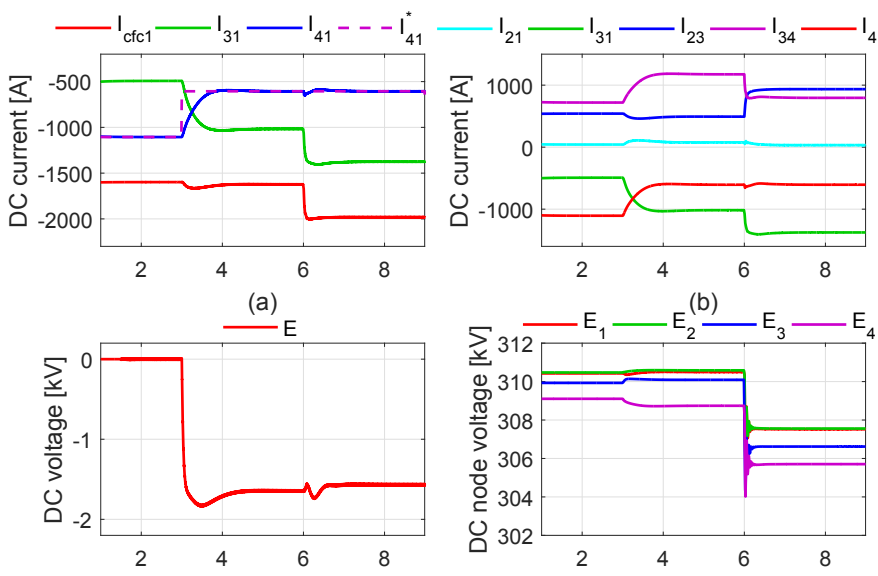

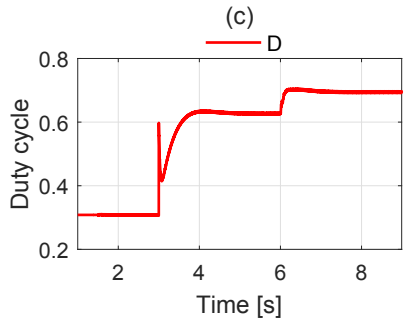

(e)

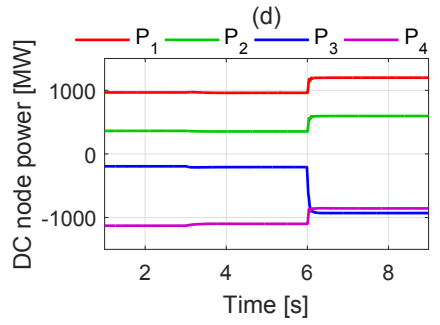

(f)
Figure 15. Simulation results. (a) CFC currents. (b) Line currents. (c) CFC voltage. (d) Node voltages. (e) Duty Cycle. (f) Node powers.

prototype of the aforementioned CFC is built and tested in a scaled down DC grid in the laboratory as the one in Fig. 16. The VSCs and the CFC can be seen in Figs. 17 and 18, respectively.

Figs. 19 and 20 depict the experimental results with the CFC in the experimental platform in the laboratory. Fig. 19 shows the results with the open-loop control with a duty cycle of the CFC set at 0.5 , which means that half of $I_{1}$ circulates through line 12 and the other half flows through 13. The CFC needs to apply certain voltages on the grid to provide this current relation and those are shown in Fig. 19 along with the line current $I_{12 p}$.

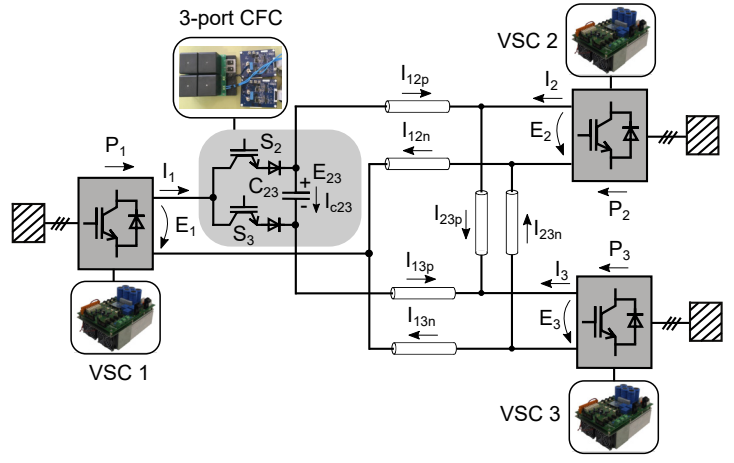

Figure 16. Scheme of the experimental 3-terminal meshed DC grid with a 3 -port CFC in the laboratory.

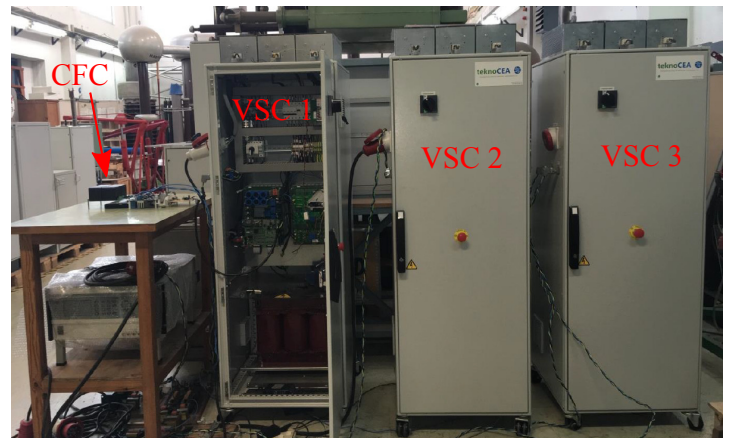

Figure 17. Image of the experimental platform, including the $\mathrm{CFC}$ and the three VSCs.

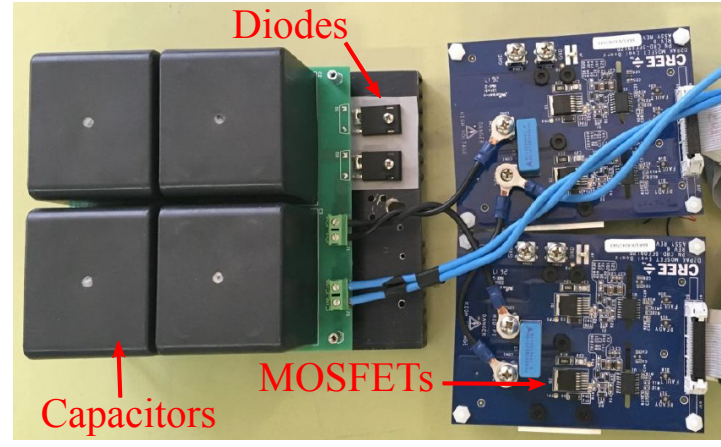

Figure 18. Detail of the CFC converter.

Fig. 20 illustrates the operation of the CFC in closed-loop current control. Initially, the CFC regulates the current $I_{12 p}$ at $0 \mathrm{~A}$, and then, the setpoint is changed to $5 \mathrm{~A}$. It can be seen that the voltage of the CFC capacitor increases its value in order to achieve such an effect and the line currents $I_{13 p}$ and $I_{23 p}$ are modified accordingly, since the same power in the nodes is maintained.

The experimental validation of the converter allows to proof the concept in a low voltage system, but substantial further work is needed in order to validate the concept at high voltage. High voltage insulation of the converter, measurements and control boards need to be addressed carefully.

\section{B. Distributed converters and selective operation}

This Section introduces the Distributed CFC (DCFC) concept, which is based on using simplified CFC devices located in different nodes and operating them selectively [57], [59]. The DCFCs are operated one at a time and this approach 


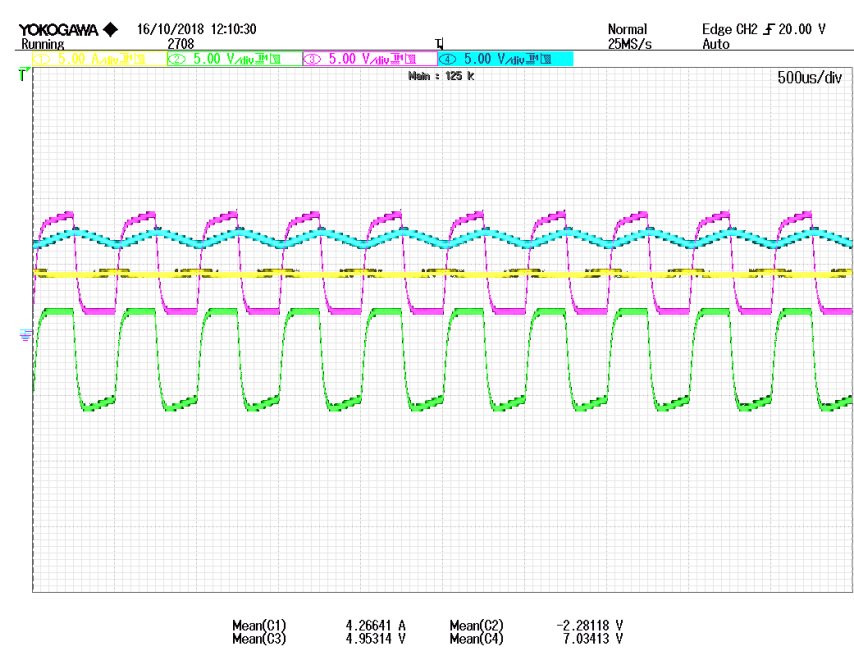

Figure 19. Experimental results showing a DC current and the voltages applied by the CFC: DC current $I_{12 p}$ (yellow), Voltage applied on line 12 (green), voltage applied on line 13 (pink) and voltage across the CFC capacitor (cyan).

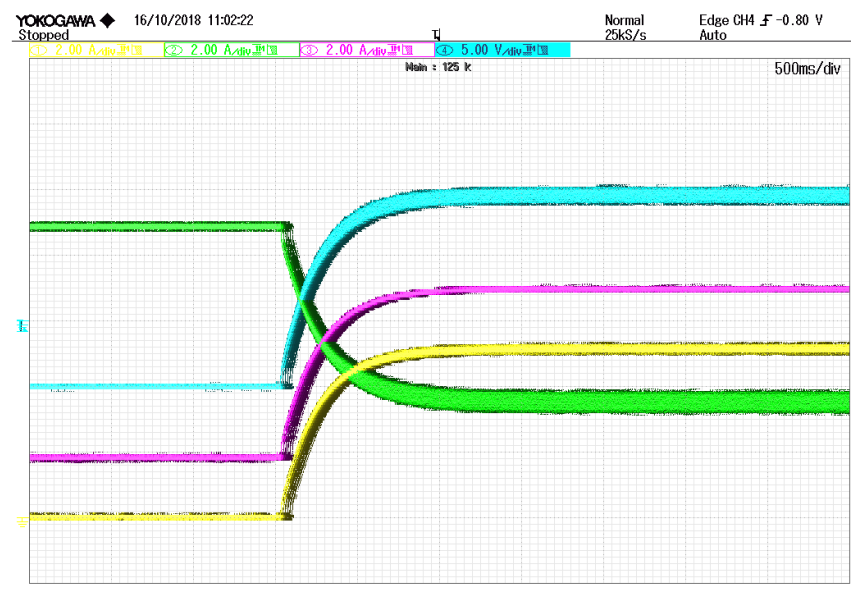

Figure 20. Experimental results showing the line currents and the $\mathrm{CFC}$ voltage: DC current $I_{12 p}$ (yellow), DC current $I_{13 p}$ (green), DC current $I_{23 p}$ (pink) and CFC voltage $E_{23}$ (cyan).

allows to use the most adequate DCFC for a given overload, which permits to control the currents with a lower CFC voltage. This work also points out the importance of choosing adequately the location and the connection scheme of the DCFCs to the HVDC grid. These DCFCs are based on the topology presented in [39], [40] and a scheme of the converter is depicted in Fig. 21(a). A possible location of those DCFCs in a 3-terminal meshed HVDC grid is illustrated in Fig. 21(b) and Fig. 22 shows the increase in the operational area brought by the DCFCs.

Considering different values of powers in Node 2 and 3 (Node 1 acts as slack bus), the light grey-filled squares depict the points where a CFC is not required since the cables of the DC grid are not overloaded. The white-filled squares show the points where some cable is overloaded and the dark greyfilled squares illustrate the points where the node current is higher than the VSCs limits. If the DCFCs cannot prevent the overload due to their voltage rating, it is indicated with a grey cross. The numbers inside the white-filled squares illustrate the node or nodes where are located the DCFCs that can prevent the overload. It can be seen that in some points two DCFCs

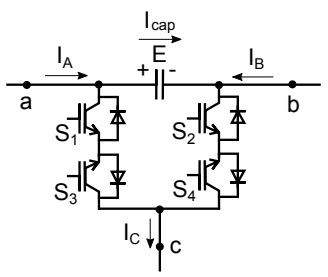

(a) (b)

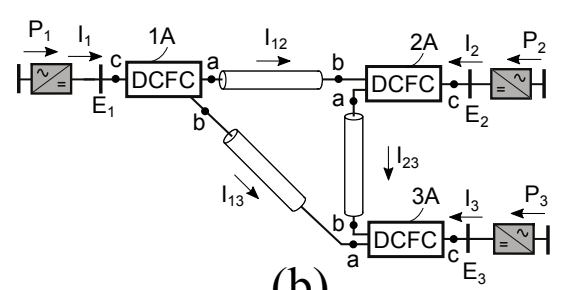

Figure 21. Distributed CFCs in the 3-terminal meshed HVDC grid. (a) Converter structure of each DCFC. (b) Scheme showing the connection of each DCFC to the meshed HVDC grid.

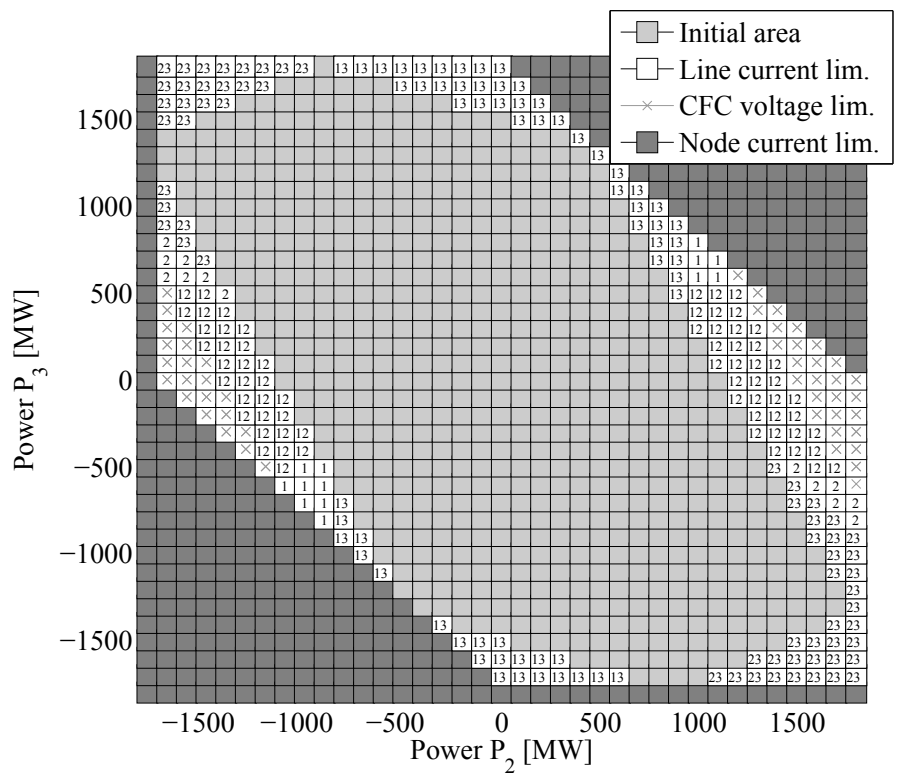

Figure 22. Increase in the operation area of the system due to the DCFC approach in Fig. 21 [57].

located in different nodes can be utilised, which introduces a redundancy that can be convenient for the controllability of the system. The DCFC concept can provide an optimum use of the CFC resources and maximise its reliability.

\section{Integration of converters and circuit breakers}

The development of both CFC and DC Circuit Breakers (DCCB) is an important step on the road to meshed HVDC grids. While the two functional aspects of CFCs and fault protection exist separately, there is opportunity to integrate the functionality into the same equipment. Some research can be found following this approach [60]-[62].

In [60], the Dual H-bridge [32] is combined with the Load Commutation Switch (LCS) of the Hybrid Circuit Breaker (HCB) [63] obtaining an integrated device that can both interrupt DC faults and has current flow control capability. The resulting circuit can be seen in Fig. 23 under a DC fault in line 12, where the two DCCB in Node 1 are combined to obtain the $\mathrm{CFC}$ device, conserving its fault protection capability.

The integration of the CFC functionality into the HCB can provide significant advantages. The CFC capability can be maintained when integrated into the breaker and a reasonable commutation time is conserved, even with the increased primary branch capacitance due to the CFC integration. The previous fact has the added benefit of reducing the peak voltage 


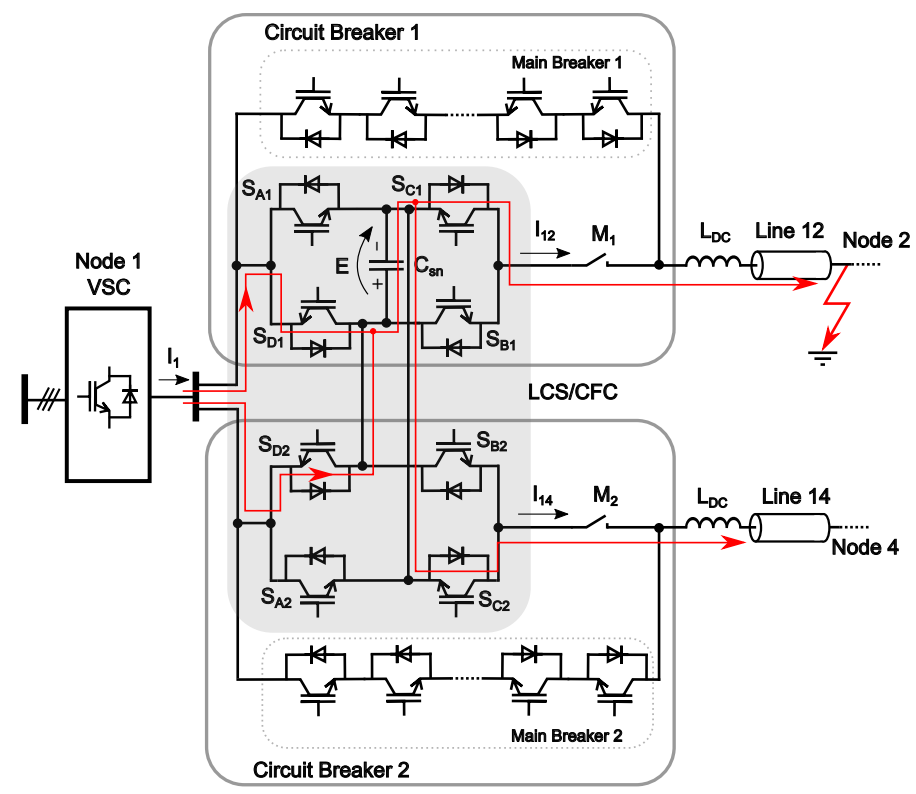

Figure 23. LCS interconnected with CFC capability. Current flow considering a fault on line 12 with the LCS/CFC switches in OFF state and the main breakers turned OFF [60].

across the LCS significantly [60]. The CFC/LCS also provides over voltage protection for the $\mathrm{CFC}$, since current is diverted away from the CFC during a DC fault. Also, the pre-charged LCS/CFC capacitance and the coupling between the two lines allows to overcome the limitations of the original LCS design, potentially resulting in faster breaking times. The integrated device brings the possibility to use the charged capacitor as a power source for other power electronics equipment that require a power source. A limitation of the design is the restart capability when the CFC is discharged.

\section{TRENDS, CHALLENGES AND RESEARCH NEEDS}

The research and development activity related to flexible DC-DC converters for HVDC grids is very linked to the feasibility of HVDC grids and Supergrids. Several studies conducted worldwide [64]-[66] support the development of HVDC grids. The development of the projects has to face important technical and non-technical barriers and there is uncertainty on how this will be conducted in the next years. Researchers from both industry and acamdemia are exploring different power electronics, protection, cable, operation and control aspects related to Supergrids. As far as flexible DCDC converters are concerned, several researchers are working on different power electronics concepts (presented in the State of the Art Section) and analyzing the system benefits of using such converters. It is worth remarking, that it is very likely that the development of these converters will be very related to the emergence of active circuit breakers, capable not only of breaking currents, but also providing the functionalities described in the paper. The main benefit of integration is that the functionalities of flexible DC-DC converters would come "for free" with two adjacent circuit breakers.

Another important trend is the study of hybrid HVDC grids using both VSC and LCC converter technologies. Hybrid configurations combine low costs and power losses from LCCs and control flexibility from VSCs. A number of applications are presented in the literature: offshore wind integration [5], [67], supply of weak grids or passive loads [68], [69] and interconnection of remote energy sources and load centers [68], [70]. Also, hybrid systems can be used to upgrade existing LCC-HVDC links, replacing one of the terminals by a VSC, or to form an HVDC grid by interconnecting existing LCC and VSC-HVDC links. In China, the first hybrid 3terminal DC grid is planned to be commissioned in 2019 [71]. This system is based on an LCC operating as rectifier and two VSCs operating as inverters and is rated to $8 \mathrm{GW}$ at $\pm 800 \mathrm{kV}$.

The main challenges related to the development of flexible DC-DC converters for HVDC grids can be summarized as follows:

- System interactions. HVDC grids have almost no inertia and multiple power electronics converters controlled by different algorithms implemented by different manufacturers. New types of oscillations and interactions are likely to occur and can challenge the practical implementation of such systems.

- Reliability enhancement. Power electronics systems are more and more reliable, but there is still uncertainty which needs to be clarified. It is fundamental to ensure that flexible DC-DC converters are extremely reliable and do not cause any problem in the system where they are installed.

- Cost. Adding equipment in a system which is already very expensive is an important challenge. While the cost of the proposed converters is low compared to MMC or circuit breakers, the option of integrating them with other equipment seems more appropriate to face this challenge.

- Integration of the proposed converters with hybrid LCCVSC schemes. Flexible DC-DC converters can provide functionalities which are very relevant for hybrid systems, which are significantly constrained (limited controllability, higher harmonic distortion, risk of commutation failure, etc.)

Significant research is required in the field to allow further development of flexible DC-DC converters for HVDC grids. The suggested research needs can be organized as follows:

- Power electronics: While there are several relevant concepts proposed, there is room for development of new enhanced converter topologies.

- Usage of modern advanced materials for the power semiconductors and for the converter passive components (capacitors and inductances). Wide bandgap semiconductors (including silicon carbide and gallium nitride) can be used in order to enhance the converter efficiency and reliability.

- Converter integration for cables and lines of different technologies.

- Power system protection: It is important to investigate different protection options to ensure the safe converter operation at a minimum additional cost. While integration with circuit breakers is a sound option, other alternatives can make sense for some applications.

- Functionalities implementation: Several studies have addressed the power flow control functionality, but there is 
limited research on how to achieve other functionalities described in the paper, like oscillation damping, pole balancing, and ancillary services provision.

- Integration of the proposed converters in existing overall voltage and power control schemes. While the proposed converter can provide some functionalities described in the paper, it will also impact the overall system power flows and voltage controls. Further research is needed to investigate optimal approaches to integrate the converter operation modes with existing overall system controllers.

- Operation and economical analysis: Simplified models of the converters need to be developed and integrated in power flow, optimal power flow and security constrained optimal power flow studies. Such studies can reveal the economical benefits of employing the converters. The development of cost models is also fundamental to analyze the economic viability of the concept.

- Integration: Integration with circuit breakers or MMC of different technologies can be further explored. Integration in hybrid LCC/VSC systems.

- Control interactions analysis: System studies considering complex systems including the proposed converters need to be studied to better understand the overall system interactions and the services that can be provided by the converter.

\section{CONCLUSION}

The paper has addressed the concept of flexible DC-DC converters for complex HVDC grids. The deployment of complex HVDC grids can trigger some challenges related to the overall system stability and control. Flexible DC-DC converters can directly control current and power in the lines, while providing several functionalities to the HVDC grid, including power flow control capability, ancillary services for the HVDC grid or adjacent grids, stability improvement, oscillation damping, pole balancing and voltage control.

The paper has summarized some advances on the proposed technology, including power electronics technical concepts, converter operation and control functionalities and integration with circuit breakers. The paper has presented the main features expected of flexible DC-DC converters (small, multifunctional, distributed, integrated, secure, efficient, reliable) and has formulated a possible vision on future complex HVDC grids.

\section{REFERENCES}

[1] D. Van Hertem, O. Gomis-Bellmunt, and J. Liang, HVDC Grids: For Offshore and Supergrid of the Future. John Wiley \& Sons, Inc., 2016.

[2] D. Jovcic and K. Ahmed, High voltage direct current transmission: converters, systems and DC grids, John Wiley \& Sons, Ed., 2015.

[3] S. Bernal-Perez, S. Ano-Villalba, R. Blasco-Gimenez, and J. RodriguezD’Derlee, "Efficiency and Fault Ride-Through Performance of a DiodeRectifier- and VSC-Inverter-Based HVDC Link for Offshore Wind Farms," IEEE Trans. Ind. Electron., vol. 60, no. 6, pp. 2401-2409, 2013.

[4] S. Foster, L. Xu, and B. Fox, "Control of an LCC HVDC system for connecting large offshore wind farms with special consideration of grid fault," in 2008 IEEE Power Energy Soc. Gen. Meet. - Convers. Deliv. Electr. Energy 21st Century, 2008, pp. 1-8.

[5] R. Zeng, L. Xu, L. Yao, S. J. Finney, and Y. Wang, "Hybrid HVDC for Integrating Wind Farms With Special Consideration on Commutation Failure," IEEE Trans. Power Deliv., vol. 31, no. 2, pp. 789-797, 2016.
[6] R. E. Torres-Olguin, M. Molinas, and T. Undeland, "Offshore Wind Farm Grid Integration by VSC Technology With LCC-Based HVDC Transmission," IEEE Trans. Sustain. Energy, vol. 3, no. 4, pp. 899-907, 2012.

[7] N. Holtsmark, H. J. Bahirat, M. Molinas, B. A. Mork, and H. K Hoidalen, "An All-DC Offshore Wind Farm With Series-Connected Turbines: An Alternative to the Classical Parallel AC Model?" IEEE Trans. Ind. Electron., vol. 60, no. 6, pp. 2420-2428, 2013.

[8] P. Lakshmanan, J. Liang, and N. Jenkins, "Assessment of collection systems for HVDC connected offshore wind farms," Electr. Power Syst. Res., vol. 129, pp. 75-82, dec 2015.

[9] M. de Prada Gil, O. Gomis-Bellmunt, A. Sumper, and J. Bergas-Jané, "Analysis of a multi turbine offshore wind farm connected to a single large power converter operated with variable frequency," Energy, vol. 36, no. 5, pp. 3272-3281, 2011.

[10] M. De-Prada-Gil, F. Díaz-González, O. Gomis-Bellmunt, and A. Sumper, "DFIG-based offshore wind power plant connected to a single VSC-HVDC operated at variable frequency: Energy yield assessment," Energy, vol. 86, pp. 311-322, jun 2015.

[11] S. Bernal-Perez, S. Ano-Villalba, R. Blasco-Gimenez, and J. RodriguezD'Derlee, "Efficiency and fault ride-through performance of a dioderectifier- and vsc-inverter-based hvdc link for offshore wind farms," IEEE Transactions on Industrial Electronics, vol. 60, no. 6, pp. 24012409, June 2013

[12] L. Yu, R. Li, and L. Xu, "Distributed pll-based control of offshore wind turbines connected with diode-rectifier-based hvdc systems," IEEE Transactions on Power Delivery, vol. 33, no. 3, pp. 1328-1336, June 2018.

[13] M. Cardiel-Alvarez, J. L. Rodriguez-Amenedo, S. Arnaltes, and M. Montilla-Jesus, "Modeling and control of lcc rectifiers for offshore wind farms connected by hvdc links," IEEE Transactions on Energy Conversion, vol. 32, no. 4, pp. 1284-1296, Dec 2017.

[14] (2019) Promotion H2020 EU project. [Online]. Available: https://www.promotion-offshore.net/

[15] R. Francoeur, "Siemens reveals dru solution for connecting offshore wind plants," Electrical Business, 2015. [Online]. Available: https://www.ebmag.com/renewables/siemens-reveals-dru-solutionfor-connecting-offshore-wind-plants-17919

[16] G. Buigues, V. Valverde, A. Etxegarai, P. Eguía, and E. Torres, "Present and future multiterminal HVDC systems : current status and forthcoming developments," Int. Conf. Renew. Energies Power Qual., vol. 1, no. 15, pp. 83-88, 2017.

[17] Friends of the Supergrid, "Roadmap to the Supergrid Technologies," Tech. Rep., 2016. [Online]. Available: https://www.friendsofthesupergrid.eu/media/technology/

[18] European Network of Transmission System Operators for Electricity(ENTSOE), "Technologies for Transmission System TYNDP 2018," Tech. Rep., 2018.

[19] D. Jovcic, "Bidirectional, High-Power DC Transformer," IEEE Trans. Power Deliv., vol. 24, no. 4, pp. 2276-2283, 2009.

[20] D. Jovcic and B. T. Ooi, "Developing DC Transmission Networks Using DC Transformers," IEEE Trans. Power Deliv., vol. 25, no. 4, pp. 25352543, 2010.

[21] E. Veilleux and B. T. Ooi, "Power flow analysis in multi-terminal HVDC grid," in 2011 IEEE/PES Power Syst. Conf. Expo. PSCE 2011, 2011, pp. $1-7$.

[22] M. Hajian, D. Jovcic, G. Asplund, and H. Zhang, "Power flow control in DC transmission grids using mechanical and semiconductor based DC/DC devices," in 10th IET Int. Conf. AC DC Power Transm. (ACDC 2012), 2012, pp. 43-43.

[23] Q. Mu, J. Liang, Y. Li, and X. Zhou, "Power flow control devices in DC grids," in 2012 IEEE Power Energy Soc. Gen. Meet., 2012, pp. 1-7.

[24] Z. Fan, G. Ning, and W. Chen, "Power flow controllers in DC systems," in Proc. IECON 2017 - 43rd Аnnu. Conf. IEEE Ind. Electron. Soc., 2017, pp. 1447-1452.

[25] P. Huang, M. S. El Moursi, and S. A. Hasen, "Novel fault ride-through scheme and control strategy for doubly fed induction generator-based wind turbine," IEEE Transactions on Energy Conversion, vol. 30, no. 2, pp. 635-645, June 2015.

[26] E. Veilleux and B. T. Ooi, "Multiterminal HVDC with thyristor powerflow controller," IEEE Trans. Power Deliv., vol. 27, no. 3, pp. 12051212, 2012.

[27] S. Balasubramaniam, J. Liang, and C. E. Ugalde-Loo, "An IGBT based series power flow controller for multi-terminal HVDC transmission," in 49th Int. Univ. Power Eng. Conf., 2014, pp. 1-5. 
[28] P. K. Barupati, S. Mukherjee, T. Jonsson, and S. Subramanian, "Seriesconnected DC/DC converter for controlling the power flow in a HVDC power transmission system WO2012037964 A1," 2010.

[29] A. Kumar and S. Mukherjee, "HVDC series current source converter US9461555 B2," 2010.

[30] J. Liang, A. Nami, F. Dijkhuizen, P. Tenca, and J. Sastry, "Current source modular multilevel converter for HVDC and FACTS," in 2013 15th Eur. Conf. Power Electron. Appl., sep 2013, pp. 1-10.

[31] W. Chen, X. Zhu, L. Yao, X. Ruan, Z. Wang, and Y. Cao, "An Interline DC Power-Flow Controller (IDCPFC) for Multiterminal HVDC System," IEEE Trans. Power Deliv., vol. 30, no. 4, pp. 2027-2036, 2015.

[32] C. Barker and R. Whitehouse, "A Current Flow Controller for Use in HVDC Grids," in 10th IET Int. Conf. AC DC Power Transm. (ACDC 2012), 2012, pp. 1-5.

[33] R. Whitehouse and C. Barker, "Current flow controller EP2670013 B1," 2012.

[34] F. Hassan, R. King, R. Whitehouse, and C. Barker, "Double modulation control (DMC) for dual full bridge current flow controller (2FB-CFC)," in 2015 17th Eur. Conf. Power Electron. Appl. (EPE'15 ECCE-Europe), 2015, pp. 1-9.

[35] S. Balasubramaniam, J. Liang, and C. E. Ugalde-Loo, "Control, dynamics and operation of a dual H-bridge current flow controller," in 2015 IEEE Energy Convers. Congr. Expo. ECCE 2015, 2015, pp. 2386-2393.

[36] S. Balasubramaniam, C. E. Ugalde-Loo, J. Liang, T. Joseph, R. King, and A. Adamczyk, "Experimental Validation of Dual H-Bridge Current Flow Controllers for Meshed HVdc Grids," IEEE Trans. Power Deliv. vol. 33, no. 1, pp. 381-392, 2018.

[37] W. Chen, X. Zhu, L. Yao, G. Ning, Y. Li, Z. Wang, W. Gu, and X. Qu, "A Novel Interline DC Power-Flow Controller (IDCPFC) for Meshed HVDC Grids," IEEE Trans. Power Deliv., vol. 31, no. 4, pp. 1719-1727, 2016.

[38] Y. Wu, H. Ye, W. Chen, and X. He, "A Novel DC Power Flow Controller for HVDC Grids with Different Voltage Levels," in 2018 Int. Power Electron. Conf. (IPEC-Niigata 2018 -ECCE Asia), 2018, pp. 2496-2499.

[39] J. Sau-Bassols, E. Prieto-Araujo, O. Gomis-Bellmunt, and F. Hassan, "Series Interline DC/DC Current Flow Controller for Meshed HVDC Grids," IEEE Trans. Power Deliv., vol. 33, no. 2, pp. 881-891, 2018.

[40] F. Hassan, J. Sau-Bassols, E. Prieto-Araujo, and O. Gomis-Bellmunt, "Current Flow Controller EP3007300 A1," 2014.

[41] "2020 climate \& energy package - Climate Action.” [Online]. Available: https://ec.europa.eu/clima/policies/strategies/2020_en

[42] X. Zhong, M. Zhu, R. Huang, and X. Cai, "Combination strategy of DC power flow controller for multi-terminal HVDC system," in 6th Int. Conf. Renew. Power Gener, 2017, pp. 1441-1446.

[43] K. H. Bhalodi, S. Mukherjee, T. Jonsson, and S. Subramanian, "An apparatus for controlling the electric power transmission in a hvdc power transmission system WO2012037967 A1," 2010.

[44] A. Acharyas, S. Mukherjee, T. Jonsson, S. Subramanian, D. Giannoccaro, and S. Auddy, "An apparatus for controlling the electric power transmission in an hvdc power transmission system WO2013139375 A1," 2012

[45] M. Ranjram and P. W. Lehn, "A three-port power flow controller for HVDC grids," in 9th Int. Conf. Power Electron. - ECCE Asia, ICPE 2015-ECCE Asia, 2015, pp. 1815-1822.

[46] V. Hofmann, A. Schon, and M. M. Bakran, "A modular and scalable HVDC current flow controller," in 2015 17th Eur. Conf. Power Electron. Appl. (EPE'16 ECCE Eur., 2015.

[47] V. Hofmann and M. M. Bakran, "An HVDC Current Flow Controller for Multi-Terminal Grids," in PCIM Eur. 2018, June 2018, Nuremberg, Ger, no. June, 2018, pp. 5-7.

[48] H. Y. Diab, M. I. Marei, and S. B. Tennakoon, "Operation and control of an insulated gate bipolar transistor-based current controlling device for power flow applications in multi-terminal high-voltage direct current grids," IET Power Electron., vol. 9, no. 2, pp. 305-315, 2016.

[49] D. Dinkel, C. Hillermeier, and R. Marquardt, "Dynamic control and design of a modular power flow controller for HVDC networks with fault clearing capabilities," in PCIM Eur. June 2018, Nuremberg, Ger. no. June, 2018, pp. 1-8.

[50] M. Ranjram and P. W. Lehn, "A Multi-port Power Flow Controller for DC Transmission Grids," IEEE Trans. Power Deliv., vol. 31, no. 1, pp. 389-396, 2016.

[51] X. Zhong, S. Member, M. Zhu, S. Member, Y. Chi, X. Du, S. Liu, and X. Cai, "Combined DC Power Flow Controller for DC Grid," in 2018 Int. Power Electron. Conf. (IPEC-Niigata 2018 -ECCE Asia). IEEJ Industry Application Society, 2018, pp. 1491-1497.
[52] K. Rouzbehi, S. S. Heidary Yazdi, and N. Shariati Moghadam, "Power Flow Control in Multi-Terminal HVDC Grids Using a Serial-Parallel DC Power Flow Controller," IEEE Access, vol. 6, pp. 56934-56944, 2018.

[53] Y. A. O. Liangzhong, C. U. I. Hongfen, L. I. Guanjun, W. Zhibing, Y. Bo, and Z. Jun, "A DC Power Flow Controller and Its Control Strategy in the DC Grid," in 2016 IEEE 8th Int. Power Electron. Motion Control Conf. (IPEMC-ECCE Asia) A, 2016, pp. 1-6.

[54] L.-E. Juhlin, "Power flow control in a meshed hvde power transmission network EP2417684 B1,” 2009.

[55] D. Giannoccaro, S. Auddya, M. Hyttinen, M. Subhasish, T. Jonsson, G. Bopparaju, and C. Heyman, "An arrangement for controlling the electric power transmission in a hvdc power transmission system EP2795758 B1,” 2011

[56] S. Mukherjee, S. Jonsson, Tomas Subramanian, and K. H. Bhalodi, "An apparatus for controlling the electric power transmission in a hvdc power transmission system WO2012037966 A1," 2010.

[57] J. Sau-Bassols, E. Prieto-Araujo, O. Gomis-Bellmunt, and F. Hassan, "Selective Operation of Distributed Current Flow Controller Devices for Meshed HVDC Grids," IEEE Trans. Power Deliv., p. Early Access, 2018.

[58] A. Mokhberdoran, J. Sau-Bassols, E. Prieto-Araujo, O. Gomis-Bellmunt, N. Silva, and A. Carvalho, "Fault mode operation strategies for dual h-bridge current flow controller in meshed hvdc grid," Electric Power Systems Research, vol. 160, pp. 163 - 172, 2018.

[59] F. Hassan, J. Sau-Bassols, E. Prieto-Araujo, and O. Gomis-Bellmunt, "Current Flow Controller Assembly EP3018786 B1," 2014.

[60] O. Cwikowski, J. Sau-Bassols, B. Chang, E. Prieto-Araujo, M. Barnes, O. Gomis-Bellmunt, and R. Shuttleworth, "Integrated HVDC Circuit Breakers With Current Flow Control Capability," IEEE Trans. Power Deliv., vol. 33, no. 1, pp. 371-380, 2018.

[61] A. Mokhberdoran, O. Gomis-Bellmunt, N. Silva, and A. Carvalho, "Current Flow Controlling Hybrid DC Circuit Breaker," IEEE Trans. Power Electron., vol. 33, no. 2, pp. 1323-1334, 2018.

[62] H. Ye, W. Chen, P. Pan, and X. He, "A Compound Controller for Power Flow and Short-circuit Fault in DC Grid," in 2018 Int. Power Electron. Conf. (IPEC-Niigata 2018 -ECCE Asia). IEEJ Industry Application Society, 2018, pp. 1504-1508.

[63] M. Callavik and A. Blomberg, "Hybrid DC Breaker," Tech. Rep., 2012

[64] D. Jovcic, D. van Hertem, K. Linden, J.-P. Taisne, and W. Grieshaber, "Feasibility of DC transmission networks," in 2011 2nd IEEE PES Int. Conf. Exhib. Innov. Smart Grid Technol., 2011, pp. 1-8.

[65] D. Van Hertem and M. Ghandhari, "Multi-terminal VSC HVDC for the European supergrid: Obstacles," Renew. Sustain. Energy Rev., vol. 14, no. 9, pp. 3156-3163, 2010.

[66] D. Bogdanov and C. Breyer, "North-East Asian Super Grid for 100\% renewable energy supply: Optimal mix of energy technologies for electricity, gas and heat supply options," Energy Convers. Manag., vol. 112, pp. 176-190, 2016.

[67] X. Li, Z. Yuan, J. Fu, Y. Wang, T. Liu, and Z. Zhu, "Nanao multiterminal VSC-HVDC project for integrating large-scale wind generation," in 2014 IEEE PES Gen. Meet. - Conf. Expo., 2014, pp. 1-5.

[68] Y. Lee, S. Cui, S. Kim, and S.-K. Sul, "Control of hybrid HVDC transmission system with LCC and FB-MMC," in 2014 IEEE Energy Conversion Congress and Exposition (ECCE). IEEE, sep 2014, pp. $475-482$.

[69] O. Kotb and V. K. Sood, "A hybrid HVDC transmission system supplying a passive load," in 2010 IEEE Electrical Power \& Energy Conference. IEEE, aug 2010, pp. 1-5.

[70] G. Tang and Z. Xu, "A LCC and MMC hybrid HVDC topology with DC line fault clearance capability," International Journal of Electrical Power \& Energy Systems, vol. 62, pp. 419-428, 2014.

[71] H. Ying, H. Weihuang, L. Ming, and L. Tao, "Steady-state Control Strategy of Multi-terminal Hybrid UHVDC Keywords Characteristic of the multi-terminal hybrid UHVDC," in 2017 19th European Conference on Power Electronics and Applications (EPE'17 ECCE Europe), Warsaw, 2017, pp. 1-10. 


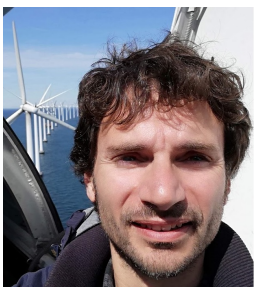

Oriol Gomis-Bellmunt (S'05-M'07-SM'12) received the degree in industrial engineering from the School of Industrial Engineering of Barcelona (ETSEIB), Technical University of Catalonia (UPC), Barcelona, Spain, in 2001 and the Ph.D. degree in electrical engineering from the UPC in 2007. In 1999, he joined Engitrol S.L. where he worked as Project Engineer in the automation and control industry. Since 2004, he has been with the Electrical Engineering Department, UPC where he is a Professor and participates in the CITCEA-UPC Research Group. His research interests include the fields linked with electrical machines, power electronics, and renewable energy integration in power systems.

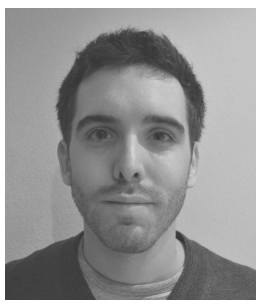

Joan Sau-Bassols (S'14) received the degree in industrial engineering from the School of Industrial Engineering of Barcelona (ETSEIB), Technical University of Catalonia (UPC), Barcelona, Spain, in 2014. He received the Ph.D. degree in Electrical Engineering also from the UPC in 2019. Since 2012, he has been with the CITCEA-UPC research group. His research interests include renewable generation systems, HVDC transmission systems, HVDC grids, current flow control, and DC/DC converters.

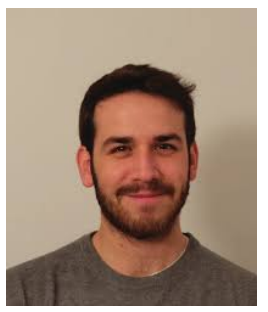

Eduardo Prieto-Araujo (S'12-M'16) received the degree in industrial engineering from the School of Industrial Engineering of Barcelona (ETSEIB), Technical University of Catalonia (UPC), Barcelona, Spain, in 2011 and the Ph.D. degree in electrical engineering from the UPC in 2016. He joined CITCEA-UPC research group in 2010 and currently he is a Serra Húnter Lecturer with the Electrical Engineering Department, UPC. His main interests are renewable generation systems, control of power converters for HVDC applications, interaction analysis between converters, and power electronics dominated power systems.

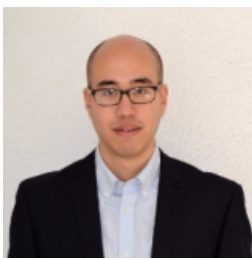

Marc Cheah-Mane (M'18) received the degree in industrial engineering from the Technical University of Catalonia (UPC), Barcelona, Spain, in 2013, and the $\mathrm{PhD}$ degree in electrical engineering from Cardiff University, Cardiff, the U.K. in 2017. Since April 2017 he is a research associate in CITCEAUPC, Barcelona, Spain. His research interests include power converters, high-voltage direct current systems, wind and photovoltaic energy. 